\title{
Problemática suscitada con la denominada reorganización simple
}

\section{Oswaldo Hundskopf Exebio}

\section{Marco legal general de la reorganización de sociedades}

Respecto del tratamiento legal correspondiente a la denominada reorganización de sociedades, se debe tomar en cuenta que la anterior Ley General de Sociedades ${ }^{1}$, siguiendo el esquema de la Ley de Sociedades Anónimas de España, de 1951, regulaba únicamente bajo esta categoría a la transformación de sociedades, en la sección segunda (artículos 346 al 353) del libro tercero, y a la fusión de sociedades, en la sección tercera (artículos 354 al 358) del mismo libro.

A partir del 1 de enero de 1998, fecha en que entró en vigencia la Ley General de Sociedades, Ley 26887 - en adelante, LGS-, existe en nuestro país una regulación moderna, sistemática y detallada de las operaciones que pueden agruparse bajo la denominación de "reorganización de sociedades".

1 Ley de Sociedades Mercantiles, Ley 16123, promulgada el 27 de julio de 1996. Posteriormente el Decreto Legislativo 311, publicado el 13 de noviembre de 1984, la modificó y la transformó en Ley General de Sociedades. Poco después, por Decreto Supremo 003-85-JUS, publicado el 13 de mayo de 1985, se aprobó el Texto Único Concordado de la Ley General de Sociedades, que estuvo vigente hasta el 31 de diciembre de 1997. 
En efecto, la Comisión Redactora de la LGS consideró conveniente incorporar una sección dedicada exclusivamente a la reorganización de sociedades, en la que se incluyó y reguló adecuadamente algunas modalidades e instituciones societarias que venían utilizándose en la praxis societaria, pero que no contaban con una regulación expresa, propuesta que fue aprobada por el Congreso de la República.

Así, actualmente, en la sección segunda del libro cuarto de la LGS se regulan, bajo el título de "Reorganización de sociedades", las siguientes modalidades o instituciones societarias:

1. La transformación (título I, artículos 333 al 343).

2. La fusión (título II, artículos 344 al 366).

3. La escisión (título III, artículos 367 al 390).

4. Otras formas de reorganización (título IV, artículos 391 al 395), que comprende: i) la reorganización simple; ii) escisiones múltiples; iii) escisiones múltiples combinadas; iv) escisiones combinadas con fusiones entre las mismas sociedades participantes; v) escisiones y fusiones combinadas entre múltiples sociedades; vi) cualquier otra operación en que se combinen transformaciones, fusiones o escisiones; vii) reorganización de sociedades constituidas en el extranjero; y viii) reorganización o transformación de la sucursal de una sociedad constituida en el extranjero.

Como es factible comprobarlo, recurriendo a la historia y a la práctica empresarial, el proceso de concentración empresarial se inicia en el siglo XIX y alcanza un auge notable en el siglo XX. Las grandes concentraciones se sucedieron unas a otras, producto de las necesidades de los empresarios por mantenerse a flote, pues los tiempos modernos les exigen a las empresas que se vayan adaptando a los cambios y exigencias que les presenta un mercado cada vez más integrado y global.

Sin embargo, si bien es cierto las concentraciones empresariales les otorgaban ciertas oportunidades de competir a las empresas pequeñas a través de la conjunción de sus fortalezas, para, de esa manera, hacer frente a las grandes corporaciones, muchas veces sucedía que las empresas perdían dinamismo debido al crecimiento repentino y, por ello, surgía la necesidad de incursionar en otros rubros de negocios, diversificación que llegaba hasta el punto de hacerse ineficientes en el mercado o a salir de este. En ese orden de ideas, la necesidad de adaptación de las sociedades a un entorno económico en permanente cam- 
bio, y la necesidad de desarrollarse con la rapidez que exige un mundo globalizado, obliga a los empresarios a reestructurar sus operaciones de manera más eficiente.

Ante tal situación, fue necesario construir modalidades o instituciones jurídicas que permitieran a los empresarios, de forma rápida y sencilla, volver al dinamismo y la eficiencia que tenían antes de producirse la concentración. En palabras de Otaegui:

La realidad es que un grado de concentración empresarial, al conllevar el inevitable gigantismo de la empresa y de la organización, requiere para el mantenimiento de su eficiencia productiva, que se proceda a una descentralización no empresarial pero sí organizativa. [...] Tanto la filial como la escisión giran en torno a la idea de que una adecuada organización de la gran empresa exige utilizar no una sociedad, sino un grupo de sociedades. Con ello se obtiene un mayor crecimiento por multiplicación, porque la excesiva centralización administrativa es un obstáculo para el desarrollo (1981, pp. 39 ss.).

Según el Diccionario de la lengua española (Real Academia Española, 2001), el término reorganización es definido como "Acción y efecto de reorganizar". El mismo diccionario contempla dos definiciones para el vocablo reorganizar: "Volver a organizar algo" y "Organizar algo de manera distinta y que resulte más eficaz". Según Enrique Elías Laroza,

[...] es un término que comprende mejor a la integridad de operaciones societarias que nos ocupan, pues se refiere a la adopción de organizaciones integradas y muchas veces múltiples, que resulten las más eficaces, y no solamente a cambios de estructura, de forma, de especie, de modelo o de sustancia. Son mutaciones que comprenden todo ello y no solamente uno o más de estos aspectos (1998, p. 665).

En cuanto a la finalidad de una reorganización de sociedades, ella es la consecuencia de muchos aspectos, pudiéndose mencionar entre ellos los siguientes:

- Aprovechamiento de economías de escala por medio de integraciones horizontales y verticales.

- Estrategias de grupos económicos.

- Racionalización de procesos productivos.

- División de áreas de negocios altamente especializados. 
- Establecimiento de estrategias de mercado.

- Multiplicación de eficiencias individuales, mediante concentración o desconcentración de la actividad empresarial.

- Solución de ineficiencias en la gestión o administración.

Por otro lado, también conviene mencionar las complejidades que se presentan en todo el proceso de reorganización: primero, la reorganización debe estar paralelamente relacionada con el objetivo buscado; segundo, la ejecución del proceso de reorganización propiamente dicha; $y$, tercero, una vez que concluye el proceso, la adecuación a la nueva forma empresarial. En resumen, cuando la administración toma la decisión de reorganizar una sociedad, debe considerar que es un mecanismo que plantea nuevos esquemas que sean productivos para el mercado en el cual se desarrollan. Como explica Pedro Flores Polo (1998):

[...] las empresas deben innovar y reconvertir sus sistemas de producción [...] podemos afirmar que la reorganización legal es una especie de "reingeniería jurídica" donde se busca el esquema de organización más adecuado para la empresa en un momento determinado. Hoy en día, los grandes grupos de empresas se fusionan, o se escinden, para reconvertirse y competir en las mejores condiciones.

Respecto de la reorganización societaria, Percy Castle Álvarez-Maza señala:

En sentido mercantil y empresarialmente hablando, la reorganización constituye un objetivo, derivado de un sinnúmero de motivos, principalmente de tipo económico y administrativo, destinado a la alteración de estructuras empresariales y legales tendientes a la concentración, división o a la eficiente prosecución de algún otro objetivo empresarial. [...] En efecto, la finalidad del derecho societario en el campo de la reorganización empresarial debe tender a generar los canales de comunicación entre los objetivos comerciales, financieros, administrativos, financieros o de cualquier otra índole que la empresa busca en su reorganización, y las estructuras legales-societarias que soportan a la empresa respectivamente, independientemente de la entidad legal que la envuelve. De ahí que la doctrina y la legislación relacionada con las distintas ciencias y disciplinas que se ocupan del fenómeno de la reorganización empresarial son, a nuestro entender, la base sobre la que se apoya la reorganización de sociedades. No podemos, por tanto, desligar una de la otra (2002, p. 256). 
Finalmente, dentro del marco legal general de la reorganización de sociedades, no se puede dejar de mencionar el Reglamento del Registro de Sociedades, aprobado por Resolución 200-2001-SUNARP/SN, publicada en el diario oficial El Peruano el 27 de julio de 2001 -en adelante, RRS-, que no siendo un reglamento propiamente dicho de la LGS, regula, según su artículo I, las inscripciones que se realizan en el Registro de Sociedades, y a las cuales se les aplican los principios registrales previstos en su texto. Es específicamente en el capítulo segundo del título IV donde se han incluido, en subcapítulos independientes, disposiciones legales sobre la transformación, la fusión, la escisión, la reorganización simple, las reorganizaciones de sociedades constituidas en el extranjero y la reorganización de sucursales establecidas en el Perú, de sociedades constituidas en el extranjero.

En esta oportunidad, y con ocasión del presente trabajo, nos circunscribiremos a la reorganización simple, pero sin limitarnos a describir su naturaleza, alcances y efectos, sino presentando lo que hemos calificado como una problemática respecto a su utilización en la praxis societaria, a raíz de la deficiente utilización de términos, refiriéndonos además, en la parte final, a los aspectos más importantes de su tratamiento tributario.

\section{La reorganización simple: concepto y elementos tipificantes}

El jurista nacional Juan Luis Hernández Gazzo indica:

[...] la reorganización simple como forma de reorganización societaria consiste en el acto mediante el cual una sociedad identifica una o más porciones de su patrimonio (bloques patrimoniales) y las transfiere (aporta) a una o más sociedades, sean éstas sociedades que ya existen o que se constituyen al efecto. La sociedad que transfiere el bloque patrimonial recibe a cambio, acciones o participaciones de la sociedad receptora del bloque, convirtiéndose, por ende, la primera en accionista o socia de la segunda, o, en caso la primera ya fuera accionista o socia de la segunda, incrementando su participación en el capital de la receptora del bloque patrimonial. La sociedad transferente del bloque no se extingue y mantiene aún cierto patrimonio (2003, pp. 1208 ss.).

Para el suscrito (Hundskopf, 2012, p. 261), la reorganización simple -denominada, por muchos, "segregación patrimonial" - consiste en la división de uno o más bloques patrimoniales de una sociedad, para 
aportarlos a una o más sociedades nuevas o existentes, recibiendo a cambio y conservando en su activo las acciones o participaciones correspondientes a dichos aportes.

Ahora bien, la principal característica que distingue a esta institución societaria de sus afines es el destino de las acciones producto de la segregación patrimonial. No sucede como en la escisión, en que la sociedad beneficiaria emite acciones a favor de los socios de la sociedad que se escinde, sino que las acciones emitidas como contraprestación al bloque patrimonial segregado son emitidas a favor de la sociedad misma. Esta idea la expresa Elías Laroza de la siguiente forma:

A ellas podría sumarse una tercera forma de escisión, que un sector de la doctrina denomina "segregación patrimonial", la que es una variante de la escisión parcial: aquí se desgajan uno o más bloques patrimoniales de una persona jurídica que no se extingue; pero las acciones o participaciones que emiten las beneficiarias se entregan a la sociedad escindente y no a sus socios (1998, p. 792).

El mismo autor desarrolla los elementos que concurren en una reorganización simple (Elías Laroza, 1998, p. 793):

a) Los bloques patrimoniales segregados pueden ser uno o más, en la misma operación.

b) La ley califica expresamente de "aportes" a las transferencias de los bloques patrimoniales a las sociedades que los reciben, sean nuevas o preexistentes.

c) La norma señala que las acciones o participaciones que emiten a cambio las sociedades receptoras corresponden a la aportante, quien las recibe y las conserva en su activo.

$\mathrm{Al}$ respecto, consideramos necesario señalar que, si bien es cierto la norma societaria peruana que regula la reorganización simple - el artículo 391 de la LGS - utiliza el término aporte, ello no significa necesariamente que toda operación de reorganización tenga un efecto económico positivo en la sociedad beneficiaria o receptora de la segregación patrimonial y que ello implique un aumento de capital en dicha sociedad.

En efecto, el término aporte no es el adecuado para definir correctamente el efecto económico de la reorganización simple en las sociedades que intervienen en dicha operación. Ello en virtud de que la racionalidad económica de una reorganización simple está dada por su naturaleza de desconcentración empresarial, la cual implica la necesidad, para algunas 
empresas, de segregar un determinado bloque patrimonial, $y$, para otras empresas, de incorporar dicho bloque patrimonial por razones de negocio que no necesariamente tienen que ver con un resultado económico inmediato a través de un aumento de capital, sino con uno a largo plazo, para lo cual estarán dispuestos a "sacrificar" aparentemente su patrimonio como consecuencia de operaciones de reorganización simple, en las cuales el valor del bloque patrimonial segregado sea negativo o neutro.

\section{Tratamiento legal específico para la reorganización simple}

La reorganización simple está regulada en el artículo 391 de la LGS:

Artículo 391.- Se considera reorganización simple el acto por el cual una sociedad segrega uno o más bloques patrimoniales y los aporta a una o más sociedades nuevas o existentes, recibiendo a cambio y conservando en su activo las acciones o participaciones correspondientes a dichos aportes.

Asimismo, el artículo 393 dispone:

Artículo 393.- Las reorganizaciones referidas en los artículos anteriores se realizan en una misma operación, sin perjuicio de que cada una de las sociedades participantes cumpla con los requisitos legales prescritos por la presente ley para cada uno de los diferentes actos que las conforman, y de que de cada uno de ellos se deriven las consecuencias que les son pertinentes.

Adicionalmente, consideramos que, aun cuando no lo mencionan expresamente los artículos transcritos, resulta aplicable por analogía al caso de la reorganización simple, atendiendo a su similitud con la escisión como forma de reorganización societaria, la definición de "bloque patrimonial" contenida en el artículo 369 de la LGS:

Artículo 369.- Para los efectos de este título, se entiende por bloque patrimonial:

1. Un activo o un conjunto de activos de la sociedad escindida;

2. El conjunto de uno o más activos y uno o más pasivos de la sociedad escindida; $\mathrm{y}$,

3. Un fondo empresarial.

Sostenemos que las definiciones contenidas en este artículo acerca de los bloques patrimoniales son perfectamente aplicables a la reorga- 
nización simple, aunque dicha norma haya sido incluida en el título correspondiente a la escisión, porque la LGS otorga a ambas figuras societarias, prácticamente, la misma naturaleza jurídica; es decir, son dos mecanismos de reorganización societaria, razón por la cual se encuentran reguladas en una misma sección, la sección segunda del libro cuarto de la LGS, manteniendo cada una sus propias particularidades. Por lo expuesto, consideramos perfectamente aplicable a la reorganización simple la definición que la LGS hace del bloque patrimonial en su artículo 369, aun cuando esta norma, como se ha mencionado, está ubicada en el título referido a la escisión como una forma específica de reorganización empresarial.

Siguiendo con el tratamiento legal de esta operación societaria, en el artículo 130 del RRS se detalla, en nueve incisos, el contenido que debe tener la escritura pública de reorganización simple; en el artículo 131 se precisa que para la inscripción de la reorganización simple no se exigirá la constancia de no haberse formulado oposición por los acreedores; en el artículo 132 se establece que si la reorganización simple diera lugar a la constitución de una nueva sociedad, se abrirá para esta una partida registral y se dejará constancia en el primer asiento de inscripción de la información exigida por la ley para la forma societaria adoptada, la fecha de entrada en vigencia de la reorganización, la identificación de la(s) sociedad(es) reorganizada(s), sus partidas registrales, y cualquier otra información que el registrador juzgue relevante, siempre que aparezca en el título que da mérito a la inscripción. Por otra parte, en el artículo 133 se regula la reorganización simple de sociedades con domicilios distintos, y en el artículo 134 se establecen las normas para las inscripciones de las transferencias de los bienes y derechos que integran el bloque patrimonial aportado.

\section{Alcances del término aporte utilizado por el artículo 391 de la LGS}

Según el profesor Elías Laroza, los aportes:

[...] constituyen los bienes, derechos o servicios, susceptibles de ser valorados económicamente, que los socios se comprometen a transferir o prestar a favor de la sociedad, para la realización del fin común objeto de la misma, generándose para los socios una obligación de dar o de hacer, según el caso, que debe cumplirse con la entrega del bien, la transferencia del derecho o la prestación del ser- 
vicio, en la forma que se haya establecido en el pacto social o en el acuerdo correspondiente. Los aportes generan un crédito en favor de los socios, que es pagado con la entrega de acciones o participaciones, las mismas que confieren a los socios todos los derechos inherentes a su condición de tales, en proporción a su participación en el capital social (1998, p. 63).

Asimismo, la LGS ha considerado la posibilidad de aportar un conjunto de bienes en calidad de bloque patrimonial, unidad económica o fondo empresarial. Esto se desprende de la lectura de su artículo 28:

Artículo 28.- Saneamiento de los aportes

El aportante asume ante la sociedad la obligación de saneamiento del bien aportado.

Si el aporte consiste en un conjunto de bienes que se transfiere a la sociedad como un solo bloque patrimonial, unidad económica o fondo empresarial, el aportante está obligado al saneamiento del conjunto y de cada uno de los bienes que lo integran.

Si el aporte consiste en la cesión de un derecho, la responsabilidad del aportante se limita al valor atribuido al derecho cedido pero está obligado a garantizar su existencia, exigibilidad y la solvencia del deudor en la oportunidad en que se realizó el aporte.

Ahora bien, como ya se ha mencionado, el artículo 391 de la LGS utiliza el término aporte para referirse al objeto de la transferencia del bloque patrimonial segregado. Al respecto, resultan ilustrativos los comentarios del profesor Elías Laroza:

Pero el destino de las acciones o participaciones de las beneficiarias, siendo una diferencia esencial, nos lleva a caracterizar a la "segregación patrimonial" (o "reorganización simple", según el artículo 391 de la LGS), como una operación que no difiere en absoluto de un simple aporte de una sociedad a otra o a otras. En efecto, este mecanismo no es otra cosa que desgajar bloques patrimoniales de una sociedad existente, quien los aporta a otras, preexistentes o nuevas, a cambio de acciones o participaciones de la sociedad o sociedades que reciben los aportes (1998, p. 792).

En el mismo sentido, Guasch Martorell indica:

[...] a diferencia de la escisión, en la segregación patrimonial (que no es cosa diferente a un normal aporte) la sociedad aportante no 
sufre merma alguna en su patrimonio, desde que, a cambio del bloque patrimonial que aporta a otra y que sale de su patrimonio, recibe, en su propio patrimonio y en compensación directa del bloque desgajado, las acciones o participaciones de la sociedad beneficiaria (1993, pp. 86 ss.).

Sin embargo, la norma societaria peruana no es del todo precisa, y en ese sentido se pronuncia Hernández Gazzo:

Teniendo en cuenta la forma como ha sido definida la reorganización simple en nuestra legislación, en principio, parecería que nos encontramos frente a un aporte de bloque patrimonial como modalidad de aumento de capital. Es así que Elías sostiene que la reorganización simple es [...] una operación que no difiere en absoluto de un simple aporte de una sociedad a otra o a otras (2003, p. 1203).

Ahora bien, como se ha señalado en el punto 3 del presente trabajo, un bloque patrimonial puede estar compuesto tanto por: i) uno o varios activos, ii) activos y pasivos, y iii) un fondo empresarial. En ese sentido, lo que normalmente ocurre es que el valor neto resultante de un bloque patrimonial sea positivo, siempre que los activos tengan mayor valor que los pasivos. Empero, puede suceder el caso de que un bloque patrimonial compuesto tanto por activos y pasivos arroje un valor neto resultante negativo o neutro, y a este respecto resulta pertinente lo que señala Julio Salas Sánchez:

[...] la circunstancia de que en la generalidad de los casos los bloques patrimoniales que se transfieren por la reorganización tengan un valor neto positivo, en el que los activos tengan un valor superior al de los pasivos que integran el mismo bloque, no debe llevar a ignorar el caso opuesto dejándolo sin regulación alguna. [...] Las partes intervinientes asumen que, a pesar de la existencia de pérdidas, la sociedad a ser absorbida tiene otros elementos o cualidades que motivan suficientemente una fusión, sea que ellos estén o no puestos de manifiesto en el respectivo balance. Más allá de las absorciones con el exclusivo propósito del arrastre fiscal de las pérdidas de la absorbida, no puede ignorarse que la absorción puede hacerse respecto de una sociedad con pérdidas, o sin ellas, que por ejemplo tiene una marca de fábrica o la concesión para su uso (2002, p. 162).

Por nuestra parte, consideramos que al haber sido regulada la segregación patrimonial (o reorganización simple) como una forma de reorganización societaria y no como una modalidad de aporte - ya que, de 
haberlo querido así, el legislador hubiera regulado esta figura en el libro segundo de la LGS, en el cual se trata a los aportes-, no podría restringirse su alcance al de un simple aporte, cuyo valor neto tendrá que ser necesariamente positivo.

Por ello, coincidimos con Hernández Gazzo cuando expresa:

Si ello hubiese sido así, esta forma de segregación patrimonial debió haberse regulado como un tipo de aporte y, por sistemática, ubicarse dentro de los aportes no dinerarios y de las modalidades de aumento de capital. [...] Empero, una interpretación sistemática y lógica debiese llevarnos a concluir que el bloque patrimonial a ser transferido mediante una reorganización simple, podrá tener valor neto positivo, negativo o neutro según los intereses de las partes involucradas (2003, p. 1217).

Debe señalarse, asimismo, que la reorganización simple, tal como ha sido regulada en nuestra LGS, permite la transferencia patrimonial a favor de la sociedad beneficiaria de forma conjunta, a través de un solo acto, mediante la dinámica de la transferencia en bloque, evitando de esta manera el ineficiente proceso de transferencia unitaria de activos, pasivos u otros elementos del patrimonio. En ese sentido se pronuncian Garrigues y Uría:

[...] el lento y dispendioso procedimiento de descomponer la transmisión patrimonial en los singulares negocios jurídicos idóneos para la transmisión de los distintos elementos integrantes del patrimonio (la compraventa, la cesión de créditos, el endoso, etc.) (1976, p. 876).

Es más, la LGS ya regula el supuesto en el cual, sea con ocasión de la constitución de una sociedad o en un aumento de capital, los suscriptores de las acciones puedan aportar un bloque patrimonial. Dicha regulación encuentra asidero en el artículo 28 de la LGS:

Artículo 28.- Saneamiento de los aportes

[...] Si el aporte consiste en un conjunto de bienes que se transfiere a la sociedad como un solo bloque patrimonial, unidad económica o fondo empresarial, el aportante está obligado al saneamiento del conjunto y de cada uno de los bienes que lo integran.

Sobre el particular, consideramos que el legislador regula expresamente una modalidad de aporte que se daba por sobreentendida, dado que nada impide a una persona transferir en calidad de aporte un conjunto de bienes no dinerarios a favor de una sociedad. Sin embargo, 
dicha modalidad de aporte estará sujeta a la valorización exigida por la misma LGS; es decir, cada bien tendrá que ser valorizado por separado e inscrito a favor de la sociedad en forma unitaria.

$\mathrm{Al}$ respecto se pronuncia Elías Laroza:

[...] la innovación introducida por la nueva ley obliga a que, además de señalar en la escritura pública los aportes, el valor de estos y el criterio utilizado para su valuación, se inserte un informe que contenga el detalle de dicha operación. Este informe servirá para dar mayor certeza respecto del valor atribuido a los aportes no dinerarios, lo cual redunda en el interés de la propia sociedad y otorga seguridad a los demás accionistas y a terceros (1998, p. 71).

Ello se explica porque lo que se busca con un aporte es esencialmente fortalecer el capital social, y debido a ello se exigen estas formalidades sobre la base del principio de integridad y realidad del capital, lo cual permitirá reflejar con mayor precisión la incidencia de los aportes en el capital de la sociedad.

Por lo tanto, cuando en virtud de lo prescrito por el artículo 28 de la LGS se aporte a una sociedad un bloque patrimonial, esta deberá emitir las acciones correspondientes, toda vez que, según Broseta Pont y Martínez Sanz, "el dinero o los bienes aportados por los socios se reflejan en la cifra de capital recogido en los estatutos" (2012, p. 357).

No habría razón entonces para regular nuevamente, en el artículo 391 de la LGS, el aporte de un bloque patrimonial. Ahora bien, en el entendido de que las normas deben interpretarse en el sentido que les otorgue eficacia normativa, consideramos que habría que entender el término aporte, empleado por el legislador, no en un sentido jurídico, sino en uno coloquial; de lo contrario, se estaría derogando en forma tácita la norma, puesto que lo supuestamente regulado por el artículo sub examine ya habría sido sancionado por el artículo 28 .

Asimismo, si al término aporte, mencionado expresamente en el artículo 391 de la LGS, le damos una interpretación literal, existirían demasiados costos de transacción que harían ineficiente dicha forma de reorganización, producto de la aplicación de las normas generales sobre aportes.

Por otro lado, cuando, producto de una reorganización simple, la sociedad que se desprende del bloque patrimonial no va a recibir acciones a cambio - es decir, el bloque tiene valor neto negativo o neutro-, existen motivos igual de legítimos para otorgar un mecanismo jurídico 
que satisfaga los intereses en juego, como por ejemplo fortalecer su patrimonio eliminando determinado bloque negativo, de tal manera que sus estados financieros reflejen un patrimonio neto más atractivo para los inversionistas de la sociedad.

Ahora bien, desde la óptica de la sociedad beneficiaria del bloque patrimonial, existen razones de negocio distintas. No habría discusión si el bloque patrimonial tiene valor neto positivo, así que no nos detendremos ahí. Sin embargo, la sociedad que integra en su estructura un bloque patrimonial negativo o neutro tiene razones igual de legítimas que las demás sociedades en aras de obtener la misma protección y beneficios legales que proporciona la LGS a estos efectos.

Entre las razones mencionadas, consideramos como las más importantes - pero no las únicas - las que representan aquellos valores que no se pueden ver reflejados en los estados financieros por su naturaleza de bienes intangibles, pero que, sin embargo, le otorgan un valor significativo al bloque patrimonial.

Tanto es así que la LGS reconoce en forma indirecta la libertad para adoptar cualquier mecanismo de valorización a la hora de determinar el valor de una empresa. De no ser ello así, toda empresa se restringiría a su valor patrimonial y no existirían incentivos para hacer empresa en el Perú, o para realizar ofertas públicas de acciones cuyo valor no sea el nominal.

$\mathrm{Al}$ respecto, Juan Mascareñas expresa:

No hay ningún método perfecto para valorar una empresa, sino que hay diferentes métodos que, más que sustitutivos, son complementarios entre sí; de tal manera que, según el tipo de empresa de que se trate, unos son mejores que otros y, en cualquier caso, unos suplen las deficiencias valorativas de los otros (2005, p. 260).

\section{La reorganización simple y el aumento de capital, en su caso}

Para que una reorganización simple implique en la sociedad absorbente un aumento de capital, el bloque patrimonial transferido debe necesariamente tener un valor neto positivo.

Solo de esta manera la sociedad receptora estará en la obligación de emitir nuevas acciones en favor de la transferente. Sin embargo, como se mencionó en el rubro anterior, el bloque patrimonial materia de una reorganización societaria puede tener valor neto negativo o neutro $y$, 
aun así, ser transferido a la sociedad receptora, situación que no implica un aumento de capital y una posterior emisión de acciones. En palabras de Julio Salas:

Distinto y opuesto es el caso en que no existe tal superávit y se está frente a un bloque cuyo valor neto es negativo. Al trasladarse las cuentas que integran ese bloque, el capital en él incorporado no existe, pues su valor ha sido íntegramente absorbido por las pérdidas o por el valor de los pasivos superior al de los activos. En este caso, nada hay por sumar ni, por ello, podrá producirse aumento alguno en el capital de la receptora. Obviamente, si no hay aumento, no habrá nuevas acciones por emitir, ni sociedad legitimada que las reciba (2002, p. 164).

Sin embargo, ello no significa necesariamente que la sociedad que se desprende del bloque patrimonial se vea perjudicada. Ya se ha mencionado que existen elementos que hacen atractivo un bloque patrimonial por más que tenga un valor contable negativo o neutro. La sociedad receptora podrá estar dispuesta a recibir una unidad de negocio contablemente negativa o neutra, pero que contenga valores intangibles que hagan que aquella esté dispuesta a otorgar acciones por ello. Citando nuevamente a Salas:

Los socios o accionistas de la receptora tendrán que atender la relación de canje con cargo a sus propias acciones o participaciones sociales. [...] Téngase presente [...] que en el caso de la fusión, el artículo 347 no exige que las acciones que correspondan a los socios o accionistas de las sociedades que se extinguen tengan la condición de acciones nuevas, de lo que puede deducirse que su legítimo derecho a ser socios de la receptora puede ser atendido entregándoles acciones en circulación (2002, p. 167).

En conclusión, resulta claro que no toda reorganización simple debe generar necesariamente un aumento de capital en la sociedad receptora del bloque patrimonial, y la consiguiente emisión de acciones a favor de la sociedad de la cual se desprende o segrega dicho bloque patrimonial, porque detrás de toda operación empresarial hay razones de negocio muy distintas, dependiendo de cuáles son los intereses de las partes en un proceso de concentración o desconcentración empresarial. 


\section{El valor del bloque patrimonial}

Desde la vigencia del actual RRS, consideramos que este tema ha quedado claramente definido, pues, en efecto, el inciso f) del artículo 130 dispone:

Reorganización simple

Artículo 130.- Contenido de la escritura pública

La escritura pública de reorganización simple a que se refiere el artículo 391 de la LGS debe contener:

$[\ldots]$

f) En caso que sea positivo el valor neto del bloque patrimonial que se aporta, el monto en que se aumenta el capital social de la sociedad que recibe el aporte y el número de las acciones o participaciones que emitirá. En caso que dicho valor sea negativo, se dejará constancia del mismo y esa circunstancia producirá que no se aumente el capital de la sociedad receptora del bloque patrimonial aportado.

Como se aprecia, el literal f) citado no deja dudas sobre la posibilidad de que el valor neto de un bloque patrimonial transferido vía reorganización simple sea negativo.

Nótese que no se menciona en forma expresa la posibilidad de que el valor neto sea neutro (cero). Sin embargo, al establecer la norma que el valor del bloque patrimonial puede ser positivo o negativo, resulta evidente que también se admite la posibilidad de que el bloque patrimonial sea neutro, equivalente a cero; es decir, ni positivo ni negativo.

Debe tenerse en cuenta que una operación de concentración o desconcentración empresarial resulta extremadamente compleja en comparación con lo sencillo que se puede presentar su explicación teórica. Por ello, el legislador no se ha visto en la necesidad de hacer mención expresa del supuesto de que el valor neto del bloque patrimonial sea neutro, ya que el derecho no debe intentar tener normas específicas para cada caso concreto. Por el contrario, en términos de buena técnica legislativa, lo aconsejable es regular supuestos generales y plantear las excepciones pertinentes hasta donde sea razonablemente posible.

Por lo tanto, en los casos excepcionales en los que estemos frente a una reorganización simple donde se pretenda transferir un bloque patrimonial con valor neto neutro, con base en una interpretación teleológica - técnica de la hermenéutica que busca extraer la finalidad de la norma - llegaremos inevitablemente a la conclusión según la cual sí 
será posible realizarla, toda vez que el propósito de la norma es regular los supuestos en los cuales no se produzca un aumento de capital por parte de la beneficiaria; en este caso, debido a que, como se ha mencionado, el bloque patrimonial segregado y recibido por la sociedad beneficiaria tiene valor neto neutro.

\section{La posible reorganización simple sin emisión de acciones}

Como indicamos en el punto anterior, el literal f) del artículo 130 del RRS se ha encargado - en nuestra opinión - de zanjar esta discusión al disponer que en una reorganización simple el bloque patrimonial transferido podrá tener valor neto negativo o neutro y, en consecuencia, en la sociedad beneficiaria del bloque no habrá aumento de capital ni se emitirán acciones, sin afectar la naturaleza jurídica de este tipo de reorganización societaria que sustenta la operación, bastando simplemente que se deje constancia de tal hecho.

A nuestro modo de ver, el reglamento hizo bien en sancionar los efectos jurídicos de esta operación, aun en el supuesto de la transferencia de un bloque patrimonial con valor neto negativo. De esta manera, el legislador registral asumió - quizá inconscientemente- una concepción subjetiva de valor, ya que quién mejor que las partes para darle contenido económico a determinados bienes.

En efecto, existen bienes cuyo valor no se desprende de una valoración objetiva, como en los casos donde lo que contablemente valdría el bloque patrimonial no se condice con el valor que representa para las partes intervinientes en la transacción. Es la voluntad negocial la que imprime un concepto de valor basado en elementos intangibles, que solo son apreciables por los agentes económicos inmersos en la operación societaria en cuestión.

\section{Desestimación de una hipotética declaración de nulidad de una reorganización simple}

La nulidad es aquella institución jurídica que sanciona con la privación de efectos jurídicos a determinados actos o negocios contrarios a la ley. El profesor Vidal Ramírez refiere:

La nulidad viene a ser entonces una sanción legal y la máxima sanción civil, cuando el acto jurídico se celebra sin sus requisitos de 
validez, o cuando se celebra con perturbaciones o distorsiones, puesto que lo priva de su existencia, validez y eficacia (2005, p. 789).

Sin embargo, al ser una de las sanciones más graves que tiene el ordenamiento legal, debe estar señalada en forma expresa. Al respecto, nos dice el mismo autor: "La enumeración de las causales es taxativa, lo que significa que el acto nulo solo puede serlo por las causales preceptuadas por el ordenamiento jurídico, pues este es el sentido adoptado por nuestro sistema legal".

Conforme a la doctrina más autorizada sobre la materia, el concepto de nulidad está comprendido en la noción más general de invalidez del negocio jurídico, que a su vez es asimilable al de la ineficacia negocial.

En efecto, para que los negocios jurídicos produzcan efectos jurídicos se necesita que cumplan con determinados requisitos de validez, además de concurrir todos sus elementos y presupuestos. Lo contrario llevaría a que los negocios jurídicos no produzcan nunca efectos jurídicos o dejen de producir aquellos que se han venido produciendo. En ambos casos, nos encontramos ante lo que se conoce como ineficacia negocial.

Taboada Córdova propone la siguiente definición de ineficacia negocial:

[...] los negocios ineficaces son aquellos que nunca han producido efectos jurídicos, o aquellos que habiéndolos producido dejan de producirlos posteriormente por la aparición de una causal sobreviniente a la celebración del mismo negocio (2002, p. 11).

Ahora bien, dentro del concepto de ineficacia del negocio jurídico se distinguen dos categorías: la primera es "ineficacia originaria", denominada también ineficacia por causa intrínseca o "ineficacia estructural"; y la segunda, "ineficacia funcional", denominada también causa extrínseca.

La categoría aplicable al presente caso es la "ineficacia original" o "ineficacia estructural", según la cual:

[...] en los supuestos de ineficacia originaria, el negocio o no produce nunca efectos jurídicos por haber nacido muerto, o deja de producir retroactivamente todos los efectos jurídicos que hubiera producido por haber nacido gravemente enfermo. La ineficacia originaria se presenta pues en dos supuestos: la nulidad y la anulabilidad, recibiendo ambas el nombre genérico de invalidez en el Código Civil peruano (Taboada, 2002, p. 12). 
La relación entre invalidez e ineficacia es desarrollada por Marcial Rubio Correa acertadamente, en los siguientes términos:

Las relaciones entre invalidez e ineficacia son claras: aquella es una de las especies de esta. En otras palabras, la invalidez es la ineficacia producida por vicios intrínsecos al acto, en tanto que la ineficacia en general es cualquier situación en la que el acto deja de producir efectos (2003, p. 13).

En términos generales, la "forma" es el "modo de emitir la declaración de voluntad, o de documentarla o de hacerla notoria a todas las personas". En otras palabras, es la manera cómo se presenta el acto jurídico frente a los demás en la vida de relación: "es el medio, o el modo, con el que se pone en ser la declaración expresa de voluntad, o sea, es el aspecto exterior que esta última asume". Ahora bien, no toda forma se constituye en requisito de validez, existiendo dos tipos de esta, cuya descripción y característica se señalan a continuación:

a) Ad probationem: se trata de una forma prescindible, en tanto se puede obviar sin que por eso se vea afectada la validez y/o eficacia del acto jurídico. Es decir, no es requisito de validez y sirve solamente para documentar la existencia del contrato.

b) Ad solemnitatem o ad substantiam: se trata una forma imprescindible y tiene un carácter constitutivo. Vale decir, constituye un requisito de validez del acto jurídico; tanto es así que su inobservancia invalida el acto por disposición expresa de la ley.

El criterio para distinguir la naturaleza de la forma de un determinado acto jurídico o contrato está contenido en el artículo 144 del Código Civil: i) será ad probationem si la ley no establece forma alguna o la señala sin sancionar su inobservancia con la nulidad del acto; y ii) será ad solemnitatem o ad substantiam si la ley señala una forma específica para la celebración del acto, sancionando su inobservancia con la nulidad.

Sin perjuicio de lo afirmado, cabe acotar que nuestro ordenamiento también permite a los particulares convenir respecto de los actos contemplados en el acápite i) del punto anterior, que estos tengan que acogerse a una determinada forma. Así lo dispone el artículo 1411 del Código Civil, con la atingencia de que tal forma voluntariamente impuesta sea acordada antes de que el propio acto sea celebrado.

En el presente caso, al no haber ninguna norma que sancione con nulidad el acuerdo por el cual, mediante reorganización simple, se 
transfiere un bloque patrimonial con valor neto negativo o igual a cero, consideramos que esa forma de reorganización es susceptible de desplegar todos los efectos jurídicos propios de esta figura societaria y, por lo tanto, se debe desestimar cualquier pretensión de nulidad de dicha operación societaria.

\section{Criterios para valorizar los bloques patrimoniales}

$\mathrm{Al}$ respecto, consideramos pertinente hacer un breve análisis acerca de los criterios de valorización, a efectos de determinar: i) el valor del bloque patrimonial, y ii) la relación de canje. Sobre el tema, Julio Salas Sánchez se pronuncia de la siguiente forma:

Sin duda que la decisión referida se toma con conocimiento de las situaciones patrimoniales de las sociedades que se reorganizan. Para llegar a la determinación del valor de la empresa o del bloque a transferir o adquirir, en su caso, se pueden usar diversos criterios de valorización. El método que se utilice arrojará un determinado valor, positivo o negativo. Pero ese valor no es, necesariamente, el que en definitiva se use para establecer la relación de canje; es decir, para determinar el número de acciones que corresponderá a los socios de la sociedad que se extingue (en la fusión y en la escisión total) o que reduce su capital (en la escisión parcial) o que recibe acciones producto del aporte en la reorganización simple. El valor establecido mediante la aplicación de cualquiera de los referidos métodos de valorización es referencial; importante, sin duda, pero referencial. A la relación de canje final se llegará luego de evaluar y negociar el valor de componentes de distinta naturaleza de las sociedades participantes, con prescindencia de que ellos se encuentren o no expresados en el balance o que hayan sido técnicamente incluidos en cualquiera de los métodos de valorización (2002, p. 163).

Nuestra LGS dedica tan solo un artículo a la reorganización simple, y en él no se hace mención al criterio de valorización que se utilizará para determinar el valor del bloque patrimonial que se transferirá.

Asimismo, el artículo 130, literal e), del RRS, que remite al artículo 27 de la LGS, menciona que la escritura pública de reorganización simple debe contener un "informe de valorización", sin especificar los criterios que se deben emplear para llegar a esta, y lo mismo sucede en el caso de la fusión y la escisión. Ese silencio del legislador tiene sentido, pues 
la intención fue dejar a la autonomía privada de las partes intervinientes la posibilidad de establecer los criterios de valorización más convenientes y que mejor reflejen la realidad patrimonial de las empresas.

Tengamos en cuenta que existen innumerables métodos de valorización, cada uno de los cuales responde a la naturaleza económica de cada realidad distinta de negocio. En nuestra opinión, hubiera sido desacertado por parte del legislador restringir los posibles criterios de valorización admitidos legalmente, al contable o patrimonial.

Consideramos, al respecto, que la LGS ha hecho bien en otorgar a las partes libertad para emplear los criterios de valorización que mejor les parezca. Ello porque quienes están en mejor posición para determinar el valor real del bloque patrimonial que será transferido son las mismas partes intervinientes.

Debe tenerse presente, asimismo, que cada bloque patrimonial puede tener un valor oculto que no se ve reflejado en los estados financieros, pero que, sin embargo, puede incrementar significativamente el valor del bloque patrimonial en cuestión.

Por lo tanto, al no haber una prohibición expresa de la norma y al estarse en el ámbito del derecho privado, las partes, con base en su autonomía privada, pueden establecer los criterios de valorización que crean más convenientes.

\section{Efectos legales de la inscripción de una reorganización simple}

Según lo descrito en el punto 6 de este trabajo, el artículo 130 del RRS autoriza a inscribir una reorganización simple en la que no haya aumento de capital, debido al valor neto negativo del bloque patrimonial que se segrega de la sociedad que se reorganiza y pasa a integrar el patrimonio de la sociedad beneficiaria.

Artículo 130.- Contenido de la escritura pública

La escritura pública de reorganización simple a que se refiere el artículo 391 de la LGS debe contener:

a) Los avisos de convocatoria, en la forma prevista en el artículo 38 de este Reglamento publicados con una anticipación no menor de tres días, salvo que se trate de juntas universales o que exista un plazo mayor establecido en el estatuto de la respectiva sociedad participante; 
b) Los acuerdos de las juntas generales de las sociedades participantes que aprueben e identifiquen la reorganización simple de manera expresa;

c) La fecha de su entrada en vigencia;

d) La declaración del gerente general, del administrador o de la persona autorizada de haber recibido el bloque patrimonial aportado, incluyendo los bienes, derechos, obligaciones y garantías que lo integran;

e) El Informe de Valorización con los datos que exige el artículo 27 de la Ley, incluyendo el valor total de los activos, de los pasivos y el valor neto del bloque patrimonial que se transfiere. Si el bloque patrimonial está integrado por pasivos y garantías, el informe tendrá igual contenido;

f) En caso que sea positivo el valor neto del bloque patrimonial que se aporta, el monto en que se aumenta el capital social de la sociedad que recibe el aporte y el número de las acciones o participaciones que emitirá. En caso que dicho valor sea negativo se dejará constancia del mismo, y esa circunstancia producirá que no se aumente el capital de la sociedad receptora del bloque patrimonial aportado;

g) El acta de la sociedad receptora del bloque patrimonial debe contener el reconocimiento y las disposiciones para el ejercicio del derecho a que se refiere el segundo párrafo del artículo 213 de la Ley, salvo que la sociedad aportante de dicho bloque no sea accionista o socia de la primera;

h) En su caso, el pacto social y el estatuto de la nueva sociedad constituida por la reorganización simple; y,

i) Los demás pactos que las sociedades participantes estimen pertinente.

Por su parte, el artículo 134 del RRS dispone:

Artículo 134.- Inscripciones de transferencia de los bienes y derechos que integran el bloque patrimonial aportado.

En mérito a la inscripción de la reorganización simple, puede solicitarse la inscripción de la transferencia de los bienes y derechos que integran los patrimonios transferidos, aunque aquellos no consten expresamente en la escritura pública de reorganización simple. 
Cuando los bienes y derechos se encuentren inscritos en Oficinas Registrales distintas a las oficinas en donde se inscribieron los actos relativos a la reorganización simple, las inscripciones se harán en mérito a la copia literal de la partida registral donde conste la inscripción de la reorganización simple y del respectivo título archivado o al instrumento público notarial que contiene la reorganización con la constancia de su inscripción.

A diferencia del caso de la escisión - que, sin perjuicio de su inmediata entrada en vigencia, está supeditada a que se produzca la inscripción de la escritura pública en el registro y en las partidas correspondientes a todas las sociedades participantes, conforme a lo dispuesto por el artículo 378 de la LGS-, en el caso de la reorganización simple - con o sin aumento de capital - la inscripción registral tiene como efecto general el de brindar oponibilidad frente a terceros a la operación; y en el caso de los bienes y derechos que integran el bloque patrimonial segregado y transferido a favor de la sociedad beneficiaria, la inscripción de la reorganización simple otorga mérito para inscribir la transferencia de dichos bienes o derechos.

\section{Tratamiento tributario de la reorganización simple de sociedades}

\section{Como explica Percy Castle Álvarez-Maza:}

[...] en materia tributaria, la presencia de una reorganización implica la aplicación normativa del "principio de neutralidad" en base al cual las disposiciones legales de carácter tributario deben evitar exigir imposición derivada de la aplicación directa de la reorganización y de los actos necesarios para efectuarla, como también evitar el beneficio directo de los contribuyentes involucrados por el mero acto de reorganización, dado que la causa del acto no tiene por finalidad obtener un beneficio económico directo (renta o consumo) del "proceso" de reorganización, sino en todo caso, de la reorganización misma. Lo contrario importaría gravar las ineficiencias y no las rentas o los consumos (2002, p. 165).

En ese sentido, el tratamiento que la reorganización societaria recibe para efectos del impuesto a la renta - en adelante, IR - e impuesto general a las ventas - en adelante, IGV - es el siguiente: 


\section{A. Impuesto a la renta (IR)}

En primer término, se debe indicar que de acuerdo con el artículo 65 del Reglamento del Impuesto a la Renta, aprobado por D.S. 122-94-EF, concordante con el artículo 103 de la Ley del Impuesto a la Renta, para los efectos de este impuesto se considera reorganización de empresas:

a) La reorganización por fusión bajo cualquiera de las dos (2) formas previstas en el artículo 344 de la LGS.

Por extensión, la Empresa Individual de Responsabilidad Limitada podrá reorganizarse por fusión de acuerdo a las formas señaladas en el artículo 344 de la citada Ley, teniendo en consideración lo dispuesto en el inciso b) del artículo 67 .

b) La reorganización por escisión bajo cualquiera de las modalidades previstas en el artículo 367 de la LGS.

c) La reorganización simple a que se refiere el artículo 391 de la LGS, así como bajo cualquiera de las modalidades previstas en el artículo 392 de la citada Ley, excepto la transformación.

d) El aporte de la totalidad del activo y pasivo de una o más empresas unipersonales, realizado por su titular, a favor de las sociedades reguladas por la LGS, teniendo en consideración lo dispuesto por el Reglamento de la Ley del Impuesto a la Renta, teniendo en consideración lo dispuesto en el inciso c) del artículo 67.

Para efectos de lo dispuesto en el citado artículo, se deberá tomar en consideración la responsabilidad solidaria prevista en el Código Tributario.

Asimismo, se entenderá que existe reorganización sólo si todas las sociedades y empresas intervinientes -incluyendo, en su caso, la sociedad o empresa que a los efectos se cree- tienen la condición de domiciliadas en el país, conforme a lo dispuesto en la Ley del Impuesto a la Renta.

Por su parte, el artículo 104 de esta ley establece que para los efectos de la reorganización societaria ( $y$, en general, para las reorganizaciones societarias en cualquiera de sus modalidades previstas en la LGS) se puede optar por cualquiera de los tres regímenes siguientes:

1) Transferir los bienes al valor que resulte de su revaluación, gravándose la diferencia entre el valor de transfe- 
rencia y el nuevo costo computable de los bienes. En este caso, el nuevo costo computable (revaluado) tiene efectos tributarios.

2) Transferir los bienes al valor que resulte de su revaluación voluntaria sin que se distribuya el mayor valor. En tal caso, el importe revaluado no mantiene efectos tributarios.

3) Cuando las sociedades involucradas en la reorganización societaria no acordaran la revaluación voluntaria de sus activos, los bienes transferidos tendrán para la empresa beneficiaria, el mismo costo computable que hubiere correspondido atribuirle en poder de la empresa transferente. Es decir, no habrá variación en el valor de los activos que conforman el bloque patrimonial transferido. Asimismo, en caso de optarse por esta alternativa, no resulta de aplicación la regla de valor de mercado contemplada en el artículo 32 de la Ley del IR.

Sobre el régimen tributario relativo a la reorganización simple de sociedades, Elías Laroza realiza los siguientes comentarios:

Históricamente, las normas tributarias otorgaron un régimen de neutralidad fiscal a los procesos de reorganización de sociedades, pero limitándolo al caso de las fusiones y "divisiones" (entiéndase como escisiones) de sociedades, no contemplando ninguna forma aplicable a las "segregaciones patrimoniales". La Ley del Impuesto a la Renta ha hecho extensivo el régimen tributario previsto para las fusiones y escisiones, al cual nos hemos referido anteriormente, a las "otras formas de reorganización" de sociedades (1998, p. 793).

De acuerdo con el artículo 65 del reglamento, se entiende como "otras formas de reorganización" a la reorganización simple prevista en el artículo 391 de la LGS, así como a las realizadas bajo cualquiera de las modalidades previstas en el artículo 392 de esta ley, excepto la transformación. Consecuentemente, las normas del IR facilitan la realización de estas formas de reorganización societaria al eliminar la aplicación del tributo a las ganancias que pudieran generarse como consecuencia de la revaluación voluntaria de los activos, siempre que a dicha revaluación no se le otorgue efectos tributarios, ya que en este supuesto surge la obligación de pagar el impuesto. 
$\mathrm{Al}$ respecto, el artículo 104 del Decreto Supremo 179-2004-EF, Texto Único de la Ley del Impuesto a la Renta, establece lo siguiente:

Tratándose de reorganización de sociedades o empresas, las partes intervinientes podrán optar, en forma excluyente, por cualquiera de los siguientes regímenes: [...] En caso que las sociedades o empresas no acordaran la revaluación voluntaria de sus activos, los bienes transferidos tendrán para la adquirente el mismo costo computable que hubiere correspondido atribuirle en poder de la transferente, incluido únicamente el ajuste por inflación a que se refiere el Decreto Legislativo $\mathrm{N}^{\circ} 797$ y normas reglamentarias.

En este caso no resultará de aplicación lo dispuesto en el artículo 32 de la citada ley. El valor depreciable y la vida útil de los bienes transferidos por reorganización de sociedades o empresas en cualquiera de las modalidades previstas en este artículo, serán determinadas conforme lo establezca el Reglamento.

Respecto de las modalidades anotadas en las que se podría concretar la reorganización de sociedades, en caso de optar por el tercer régimen no se generarían efectos respecto del IR; se entendería que la transferencia de activos no generaría rentas gravables y, tampoco, la obligación de aplicar la regla de valor de mercado.

Por otra parte, se debe tener presente que las normas del IR establecen que la reorganización de sociedades surtirá efectos en la fecha de entrada en vigencia fijada en el respectivo acuerdo, siempre que haya sido comunicada a la Sunat dentro de los diez días hábiles siguientes. En caso de no haberse cumplido con esa comunicación, la reorganización de sociedades tendrá efectos a partir de la fecha de otorgamiento de la escritura pública².

2 El artículo 73 del Decreto Supremo 122-94-EFE, Reglamento de la Ley del Impuesto a la Renta, establece: “Artículo 73.- FECHA DE ENTRADA EN VIGENCIA DE LA REORGANIZACION. La fusión y/o escisión y demás formas de reorganización de sociedades o empresas surtirán efectos en la fecha de entrada en vigencia fijada en el acuerdo de fusión, escisión o demás formas de reorganización, según corresponda, siempre que se comunique la mencionada fecha a la SUNAT dentro de los diez (10) días hábiles siguientes a su entrada en vigencia. De no cumplirse con dicha comunicación en el mencionado plazo, se entenderá que la fusión y/o escisión y demás formas de reorganización correspondientes surtirán efectos en la fecha de otorgamiento de la escritura pública. En los casos en que la fecha de entrada en vigencia fijada en los acuerdos respectivos de 
B) Impuesto general a las ventas (IGV)

El artículo 2.c de la Ley del Impuesto General a las Ventas dispone que las transferencias de bienes que se realicen con motivo de la reorganización de empresas están inafectas a dicho impuesto. Al respecto, las normas reglamentarias del IGV (artículo 2.7) establecen que se entiende por reorganización de empresas la reorganización de sociedades y empresas a las que se refieren las normas que regulan el IR ${ }^{3}$.

Con la esperanza de haber cumplido con el objetivo que nos propusimos en este artículo, estamos convencidos de que, dadas las particularidades de la reorganización simple y su propia problemática, no dudamos de que seguramente surgirán en el futuro nuevos temas de interés.

\section{Referencias}

Broseta Pont, M., \& Martínez Sanz, F. (2012). Manual de derecho mercantil (volumen I). Madrid: Tecnos.

Castle Álvarez-Maza, P. (2002). ¿La reorganización simple o simple aporte? Advocatus, 7. Lima.

Elías Laroza, E. (1998). La Ley General de Sociedades comentada. Trujillo: Normas Legales S. A.

Flores Polo, P. (1998). Nuevo derecho societario peruano: nueva Ley General de Sociedades: principales modificatorias. Lima: Cámara de Comercio de Lima.

Garrigues J., \& Uría, R. (1976). Comentario a la Ley de sociedades anónimas. Madrid: Aguirre.

fusión y/o escisión u otras formas de reorganización sea posterior a la fecha de otorgamiento de la escritura pública, la fusión y/o escisión y demás formas de reorganización surtirán efectos en la fecha de vigencia fijada en los mencionados acuerdos. En estos casos se deberá comunicar tal hecho a la SUNAT dentro de los diez (10) días hábiles siguientes a su entrada en vigencia".

3 El artículo 2 del Decreto Supremo 29-94-EF, Reglamento de la Ley del Impuesto General de las Ventas e Impuesto Selectivo al Consumo, establece:

"Artículo 2.- Para la determinación del ámbito de aplicación del Impuesto, se tendrá en cuenta lo siguiente: [...]

7. Reorganización de empresas:

Para efectos de este impuesto, se entiende por reorganización de empresas: a) A la reorganización de sociedades o empresas a que se refieren las normas que regulan el Impuesto a la Renta [...]". 
Guasch Martorell, R. (1993). La escisión de sociedades en el derecho español. Madrid: Civitas.

Hernández Gazzo, J. L. (2003). Apuntes sobre la reorganización simple en la legislación peruana. En Tratado de derecho mercantil. Tomo I. Derecho societario. Lima: Gaceta Jurídica.

Hundskopf Exebio, O. (2012). Manual de derecho societario. (2. ${ }^{\mathrm{a}}$ ed.). Lima: Gaceta Jurídica.

Mascareñas, J. (2005). Fusiones y adquisiciones de empresas. Madrid: McGraw-Hill.

Otaegui, J. (1981). Fusión y escisión de sociedades comerciales. Buenos Aires: Ábaco.

Real Academia Española. (2001). Diccionario de la lengua española. (22. ${ }^{\text {a }}$ ed.). Madrid: Espasa.

Rubio Correa, M. (2003). Nulidad y anulabilidad: la invalidez del acto jurídico. Lima: Pontificia Universidad Católica del Perú, Fondo Editorial.

Salas Sánchez, J. (2002). El valor neto negativo del bloque patrimonial que se transfiere en los procesos de reorganización societaria. Ius et Veritas, 25.

Taboada Córdova, L. (2002). Nulidad del acto jurídico. (2. ${ }^{\mathrm{a}}$ ed.). Lima: Grijley.

Vidal Ramírez, F. (2005). El acto jurídico. (6. ${ }^{\mathrm{a}}$ ed.). Lima: Gaceta Jurídica. 
